\title{
Chemoradiotherapy with capecitabine for locally advanced anal carcinoma: an alternative treatment option
}

\author{
D Meulendijks ${ }^{1,2,3}$, L Dewit ${ }^{4}$, N B Tomasoa ${ }^{4}$, H van Tinteren ${ }^{5}$, J H Beijnen ${ }^{6,7}$, J H M Schellens ${ }^{1,2,7}$ and A Cats ${ }^{\star, 3}$ \\ ${ }^{1}$ Division of Clinical Pharmacology, Department of Medical Oncology, The Netherlands Cancer Institute, Amsterdam, \\ The Netherlands; ${ }^{2}$ Department of Molecular Pathology, The Netherlands Cancer Institute, Amsterdam, The Netherlands; \\ ${ }^{3}$ Division of Gastroenterology and Hepatology, Department of Medical Oncology, The Netherlands Cancer Institute, Amsterdam, \\ The Netherlands; ${ }^{4}$ Department of Radiation Oncology, The Netherlands Cancer Institute, Amsterdam, The Netherlands; \\ ${ }^{5}$ Department of Biometrics, The Netherlands Cancer Institute, Amsterdam, The Netherlands; ${ }^{6}$ Department of Pharmacy \\ \& Pharmacology, Slotervaart Hospital, Amsterdam, The Netherlands and ${ }^{7}$ Faculty of Science, Department of Pharmaceutical \\ Sciences, Division of Pharmacoepidemiology and Clinical Pharmacology, Utrecht University, Utrecht, The Netherlands
}

Background: Capecitabine is an established treatment alternative to intravenous 5-fluorouracil (5-FU) for patients with rectal cancer receiving chemoradiotherapy. Its place in the treatment of locally advanced anal carcinoma (AC), however, remains undetermined. We investigated whether capecitabine is as effective as 5-FU in the treatment of patients with locally advanced AC.

Methods: One hundred and five patients with squamous cell AC stage T2-4 (T2>4 cm), N0-1, M0 or T1-4, N2-3, M0, were included in this retrospective study. Forty-seven patients were treated with continuous 5-FU $\left(750 \mathrm{mg} \mathrm{m}^{-2}\right)$ on days $1-5$ and $29-33$, mitomycin $\mathrm{C}$ (MMC, $\left.10 \mathrm{mg} \mathrm{m}^{-2}\right)$ on day 1, and radiotherapy; 58 patients were treated with capecitabine $\left(825 \mathrm{mg} \mathrm{m}^{-2}\right.$ b.i.d. on weekdays), MMC $\left(10 \mathrm{mg} \mathrm{m}^{-2}\right)$ on day 1, and radiotherapy. The primary end points of the study were: clinical complete response rate, locoregional control (LRC) and overall survival (OS). Secondary end points were: colostomy-free survival (CFS), toxicity and associations of genetic polymorphisms (GSTT1, GSTM1, GSTP1 and TYMS) with outcome and toxicity.

Results: Clinical complete response was achieved in 41/46 patients (89.1\%) with 5-FU and in 52/58 patients (89.7\%) with capecitabine. Three-year LRC was $76 \%$ and $79 \%(P=0.690$, log-rank test), 3-year OS was $78 \%$ and $86 \%(P=0.364$, log-rank test) and CFS was $65 \%$ and $79 \%(P=0.115$, log-rank test) for 5 -FU and capecitabine, respectively. GSTT1 and TYMS genotypes were associated with severe (grade 3-4) toxicity.

Conclusions: Capecitabine combined with MMC and radiotherapy was equally effective as 5-FU-based chemoradiotherapy. This study shows that capecitabine can be used as an acceptable alternative to 5-FU for the treatment of AC.

Anal carcinoma $(\mathrm{AC})$ is a relatively rare malignancy with an annual incidence of $\sim 1$ in 100000 in European countries (Netherlands Cancer Registry). Treatment of locally advanced disease evolved from abdominoperineal resection to sphincterpreserving radiotherapy by the late 1970s. It was subsequently shown by Nigro et al in 1983, and later confirmed in two pivotal randomised controlled trials (RCTs), that radiotherapy with concomitant 5-fluorouracil (5-FU) and mitomycin C (MMC) resulted in superior disease control compared with radiotherapy alone (Nigro et al, 1983; UKCCCR Anal Cancer Trial Working Party, 1996; Bartelink et al, 1997). Nowadays, the standard of care is full-dose radiation therapy combined with 5-FU, administered as a continuous infusion for 4 or 5 days in week 1 and 5 of radiotherapy, and MMC as a bolus on day 1 (James et al, 2013).

*Correspondence: Dr A Cats; E-mail: a.cats@nki.nl

Received 19 April 2014; revised 5 July 2014; accepted 26 July 2014; published online 28 August 2014

(c) 2014 Cancer Research UK. All rights reserved 0007-0920/14 
Radiotherapy is usually applied using a two- or three-field technique to a total dose of 45-50.4 Gy in 4-5 weeks, sometimes followed by a boost up to 59.4 Gy (UKCCCR Anal Cancer Trial Working Party, 1996; Bartelink et al, 1997; Gunderson et al, 2012) or, more recently, as intensity-modulated radiation therapy (IMRT) (Pepek et al, 2010; Bazan et al, 2011).

Capecitabine is an oral 5-FU pre-prodrug, which offers an alternative to 5-FU that does not require inpatient hospital care, is more convenient for patients and reduces the costs of treatment. In addition, by administering capecitabine on all radiation days, a longer duration of exposure to 5-FU and its cytotoxic metabolites during irradiation can be achieved, thereby potentially increasing the radiosensitising effect.

In a recent non-inferiority study, the efficacy of capecitabine in the neoadjuvant treatment with chemoradiation of locally advanced rectal cancer has been demonstrated (Hofheinz et al, 2012). In AC, however, RCTs are difficult to perform because of its low incidence and a relatively low failure rate. Indeed, capecitabine-based chemoradiation in AC has been investigated in only a few small studies (Glynne-Jones et al, 2008; Deenen et al, 2013).

To investigate the effectiveness of capecitabine, we performed a retrospective study to determine clinical complete response (cCR) rate, locoregional control (LRC) and overall survival (OS) in consecutive patients treated with capecitabine, MMC and IMRT, and compared outcomes with patients treated with 5-FU-based chemoradiotherapy.

\section{MATERIALS AND METHODS}

Patient characteristics. All consecutive patients, $\geqslant 18$ years of age, with histologically confirmed locally advanced squamous cell AC, classified as T2-4 (with T $>4 \mathrm{~cm}$ ), N0-1 and M0, or T1-4 with N2-3 and M0) treated at our institute between August 2003 and August 2011 with concurrent chemoradiotherapy were included. Patients with a history of other malignancies (except resectable basal cell or squamous cell carcinoma of the skin), patients with recurrent disease at presentation and patients receiving chemotherapy other than a fluoropyrimidine + MMC were excluded. Disease staging was performed according to the American Joint Committee on Cancer staging manual (6th edition) and the International Union Against Cancer system. The study was approved by the institutional ethics committee.

\section{Treatments}

Radiotherapy. Patients treated before March 2006 received threedimensional conformal radiotherapy (CF-RT), whereas subsequent patients received simultaneous integrated boost IMRT. With CF$\mathrm{RT}$, the primary tumour and elective pelvic and inguinal lymph nodes (LNs) were irradiated to a dose of $45 \mathrm{~Gy}$ ( 25 fractions of $1.8 \mathrm{~Gy}$ ). After a planned rest period of 3 weeks, a boost of 8-11 fractions of $1.8 \mathrm{~Gy}$ was delivered to the primary tumour and macroscopically involved LNs. The number of fractions of the boost ( 8 in case of cCR, 11 in case of partial response) was determined by digital rectal examination (DRE), and MRI of the pelvis, if required, in week 5. Patients treated with IMRT received a total dose of $59.4 \mathrm{~Gy}(33 \times 1.8 \mathrm{~Gy})$, delivered on weekdays in 6.5 consecutive weeks, without planned treatment break. Pelvic and inguinal LNs were electively irradiated to a total dose of $49.5 \mathrm{~Gy}(33 \times 1.5 \mathrm{~Gy})$. Here also, the decision to give an additional boost of $3 \times 1.8$ Gy was based on DRE and pelvic imaging, if required, in week 5 .

Chemotherapy. Between August 2003 and January 2008, chemotherapy consisted of 5 -FU in all patients, given as a continuous infusion of $750 \mathrm{mg} \mathrm{m}^{-2}$ on days 1-5 (in week 1) and days 29-33 (in week 5) of radiation treatment. In February 2008, a phase I dose-escalation study was initiated using capecitabine instead of 5-FU (Deenen et al, 2013). From February 2008 onward, all patients received capecitabine, except six patients who were not included in the study and received 5-FU (this included three HIV-positive patients and one patient considered unable to comply with instructions for taking oral medication). Patients received $825 \mathrm{mg} \mathrm{m}^{-2}$ capecitabine b.i.d. on radiation days, except during the three boost fractions. Patients with a body surface area (BSA) $>2.0 \mathrm{~m}^{-2}$ were dosed according to BSA $2.0 \mathrm{~m}^{-2}$. All patients received $10 \mathrm{mg} \mathrm{m}^{-2} \mathrm{MMC}$ as an intravenous bolus injection on day 1 , with a maximum of $15 \mathrm{mg}$. The durations of unscheduled treatment interruptions for radiotherapy and chemotherapy were recorded, as were the reasons for deviating from the treatment protocol.

Toxicity evaluation. During chemoradiotherapy, acute toxicity was recorded and discussed weekly during the multidisciplinary treatment discussion. Acute toxicity was assessed retrospectively within four domains (dermatological, gastrointestinal, haematological and genitourinary) according to the NCI-CTCAE, v3.0. Toxicities were scored as worst grade occurring from start of treatment until 30 days after the last fraction of radiotherapy.

Response evaluation and follow-up. Tumour response was evaluated by DRE and palpation of inguinal nodes during treatment, at the end of treatment, and 4-6 weeks after completion of treatment. Clinical complete response was defined as complete resolution of palpable tumour by physical examination. Patients were included for evaluation of clinical response if there was at least 12 weeks of follow-up available. Follow-up evaluation at the outpatient clinic included physical examination and laboratory analysis, including squamous cell carcinoma antigen as a tumour marker, and was performed every 3 months during the first 2 years after treatment, every 6 months in the third year and once a year thereafter. In case of suspected recurrence, additional imaging and histological confirmation were performed.

Pharmacogenetics. Polymorphisms in the gene encoding thymidylate synthase (TYMS) and in genes encoding glutathione S-transferase enzymes have been associated with outcome and toxicity in patients treated with fluoropyrimidines and radiotherapy (Pullarkat et al, 2001; Ambrosone et al, 2006; Mahimkar et al, 2011). We analysed associations with response and toxicity for the following polymorphisms: GSTT1 (deletion), GSTM1 (deletion), GSTP1 313A > G, TYMS 3'UTR 6-bp ins/del and TYMS $5^{\prime}$ UTR variable number of 28 -bp tandem repeats (VNTR). With regard to the TYMS VNTR polymorphism, patients were categorised as having low expression $\left({ }^{\star} 2 /{ }^{\star} 2,{ }^{\star} 2 /{ }^{*} 3 \mathrm{C}\right.$ or $\left.{ }^{\star} 3 \mathrm{C} /{ }^{\star} 3 \mathrm{C}\right)$ or high expression genotypes $\left({ }^{\star} 2 /{ }^{*} 3 \mathrm{G},{ }^{*} 3 \mathrm{C} /{ }^{*} 3 \mathrm{G}\right.$ or $\left.{ }^{\star} 3 \mathrm{G} /{ }^{*} 3 \mathrm{G}\right)$ based on the G>C SNP in the second repeat (Mandola et al, 2003). Polymorphisms in GSTT1 and GSTM1 were determined by polymerase chain reaction (PCR) and visualisation of PCR products on agarose gel, GSTP1 313A $>\mathrm{G}$ was determined using a commercial real time PCR assay and polymorphisms in TYMS were assessed by PCR and sequencing (primer sequences available on request).

End points and statistical considerations. The primary end points were cCR rate, LRC and OS. Colostomy-free survival (CFS) and acute toxicity were secondary end points. Baseline patient and disease characteristics were compared using Student's $t$-test, Mann-Whitney $U$-test, Fisher's exact test or $\chi^{2}$ whenever appropriate. The Kaplan-Meier method was used to determine LRC, OS and CFS. Time to locoregional failure was defined as the interval between treatment day 1 and the day on which clinical signs of progression at the primary site or regional LNs (inguinal or pelvic) first occurred. Time to colostomy was defined as the interval between treatment day 1 and the day of surgery for colostomy. Pretreatment colostomies were considered tumour-related 
colostomies at $t=0$. Pretreatment colostomies that were reversed during follow-up were ignored and not considered to be an event in the analysis. A colostomy was classified as treatment-related if it was performed either during chemoradiotherapy or after the completion of therapy, in absence of histologic evidence of disease. Overall survival was calculated from the first treatment day till the day of death. Patients that did not experience an event were censored at the day of last follow-up. Groups were compared using log-rank tests. Fisher's exact test was used to assess toxicity between groups as a dichotomised outcome (none or grade 1-2 toxicity $v s$ grade $\geqslant 3$ toxicity). All statistical tests were two-sided with significance set at $P<0.05$. All analyses were performed using SPSS 16.0 (SPSS Inc, Chicago, IL, USA).

\section{RESULTS}

Patient and treatment characteristics. A total of 129 AC patients were identified, 63 were treated with 5-FU and 66 with capecitabine. Sixteen patients within the 5-FU group were excluded, for the following reasons: metastatic disease (7), concurrent other malignancy (3), recurrent disease at presentation (3), patient record not available (2) and treatment with cisplatin (1). Eight patients were excluded from the capecitabine group, for: metastatic disease (5), recurrent disease (2) and concurrent other malignancy (1). The first 18 patients within the capecitabine group were treated in a phase I study that was reported previously (Deenen et al, 2013). Seven of these patients, which were included in the analysis, received a dose lower than $825 \mathrm{mg} \mathrm{m}^{-2}$ bid (500-650 $\mathrm{mg} \mathrm{m}^{-2}$ bid). There were no significant differences between groups in baseline patient and disease characteristics (Table 1). One patient in the capecitabine group was identified with a heterozygous $D P Y D^{\star} 2 A$ mutation and was treated with a $50 \%$ reduced dose of capecitabine.

Compliance with treatment plan. All patients completed radiotherapy. Radiotherapy was completed without interruptions in $43 / 47$ (92\%) of the patients in the 5-FU group and in 55/58 (95\%) of the patients in the capecitabine group. Planned chemotherapy was completed without interruptions in $45 / 47$ (96\%) of the patients in the 5-FU group and in 50/58 (86\%) of the patients in the capecitabine group. Delays lasted between 11-12 days with 5-FU (median: 11.5 days) and 1-14 days with capecitabine (median: 3 days). Of the planned cumulative dose, all patients in the 5-FU group received $100 \%$; in the capecitabine group patients received on average $95 \%( \pm 15 \%)$.

Toxicity evaluation. Acute toxicity tended to be more prevalent in the capecitabine group (Table 2 ), with grade $\geqslant 3$ radiation dermatitis occurring significantly more often with capecitabine than with 5 -FU. In the 5-FU group, the incidence of grade $\geqslant 3$ radiation dermatitis was not affected by radiation technique (13\% for both 5-FU/CF-RT and 5-FU/IMRT). Grade 4 toxicity occurred in 2/47 patients (4\%) that were treated with 5-FU (both haematological toxicities), leading to delay of chemo- and radiotherapy in one case. Grade 4 toxicities occurred in 5/58 patients (9\%) treated with capecitabine (two dermatological, two haematological, and one gastrointestinal toxicity), leading to the delay of chemo- and radiotherapy in two cases (the other toxicities occurred at the end of the treatment period or before a weekend break). No toxic deaths were observed.

Response evaluation. All patients except one were considered for response evaluation (one patient in the 5-FU group was lost to follow-up 11 weeks after end of treatment). In the 5-FU group $41 / 46$ patients $(89 \%)$ and in the capecitabine group $52 / 58$ patients (90\%) reached a cCR, at a median of 3 weeks (range: $-2-22$ ) and 3 weeks (range: $-3-28$ ) after the last treatment day, respectively.
When calculated from the first day of treatment, patients in the capecitabine group reached cCR earlier than patients in the 5-FU group (69 days vs 93 days, $P=0.015$, Mann-Whitney $U$-test). Characteristics of the patients that did not reach cCR are summarised in Table 3. Rates of cCR did not differ significantly between 5-FU/CF-RT, 5-FU/IMRT, and capecitabine/IMRT subgroups (88\%, 87\%, 90\%, respectively; $P=0.926)$.

Survival parameters. With a median duration of follow-up of 49 months (range: 4-96) in the 5-FU group and 23 months (range: 13-54) in the capecitabine group, LRC did not differ between groups; 3-year LRC rates were 76\% (95\% CI: 60\%-92\%) and 79\% (95\% CI: $57 \%-101 \%)$ for 5-FU and capecitabine, respectively $(P=0.690$, Figure 1A). The 3 -year CFS was $65 \%$ (95\% CI: $44 \%-$ $86 \%)$ and $79 \%(95 \% \mathrm{CI}: 56 \%-102 \%)$ for 5 -FU and capecitabine, respectively ( $P=0.155$, Figure 1B). Four pretreatment colostomies in the 5-FU group and one in the capecitabine group were reversed during follow-up. Treatment-related colostomies occurred in the 5 -FU group in four cases (9\%) and in the capecitabine group in one case $(2 \%)$. Overall surival was not significantly different between groups, 3-year OS was 78\% (95\% CI: 64\%-92\%) and 86\% (95\% CI: $68 \%-104 \%)$ for 5 -FU and capecitabine, respectively $(P=0.364$, Figure 1C). There were no significant differences between the 5-FU/CF-RT, 5-FU/IMRT, and capecitabine/IMRT groups with regard to LRC and OS (Figure $2 \mathrm{~A}$ and $\mathrm{B}$ ). Pairwise comparisons showed that the 5-FU/IMRT and capecitabine/IMRT groups were not significantly different with regard to LRC and OS ( $P=0.577$ and $P=0.809$, respectively). Comparisons with the 5 -FU/CF-RT group also showed no significant differences (data not shown).

Pharmacogenetics. Table 4 shows the associations of polymorphisms with clinical response and toxicity. No associations with response were observed. However, the TYMS VNTR polymorphism was associated with severe toxicity; $40 \%$ of the patients with a low expression genotype experienced grade 3-4 toxicity $v$ s $18 \%$ of the patients with a high expression genotype. When different types of toxicity were considered separately (Table 5), patients with the low expression genotype more often experienced severe dermatological, gastrointestinal, genitourinary toxicity, although the differences for the individual toxicities did not reach statistical significance. The GSTT1 NULL genotype also tended to be associated with increased overall toxicity. There was a significant association between the GSTT1 NULL genotype and dermatological toxicity; $43 \%$ of these patients experienced severe dermatological toxicity, compared with $19 \%$ of the patients without the NULL genotype ( $P=0.040$, Fisher's exact test).

\section{DISCUSSION}

We show in a cohort of consecutively treated patients with locally advanced AC that, in combination with full-dose radiation therapy, comparable cCR rate, LRC, and OS can be achieved with capecitabine as with 5-FU. The cCR rate ( $\sim 90 \%)$, 3-year LRC (75\%-80\%), and 3-year OS (80\%-85\%) compare favourably with other studies (UKCCCR Anal Cancer Trial Working Party, 1996; Bartelink et al, 1997; James et al, 2013). Capecitabine was given on all radiation days, thereby achieving a longer duration of interaction between radiosensitising chemotherapy and radiation. All patients completed radiotherapy, and on average $95 \%$ of the planned dose of capecitabine could be administered.

Although the incidence of severe toxicity was generally low, grade 3-4 dermatological toxicity was with $31 \%$ far more frequent in patients treated with capecitabine and radiotherapy than in patients treated with 5-FU and radiotherapy (13\%). Most likely this is due to longer duration of combined exposure to chemotherapy and radiation with bi-daily capecitabine, and not due to differences 
Table 1. Patient and treatment characteristics

\begin{tabular}{|c|c|c|c|c|c|}
\hline \multirow[b]{2}{*}{ Characteristic } & \multicolumn{2}{|c|}{$5-\mathrm{FU}+\mathrm{MMC}(n=47)$} & \multicolumn{2}{|c|}{ Capecitabine + MMC $(n=58$} & \multirow[b]{2}{*}{$P$-value } \\
\hline & No. & $\%$ & No. & $\%$ & \\
\hline Age (years), median (range) & \multicolumn{2}{|c|}{$53.5(36.8-83.8)$} & \multicolumn{2}{|c|}{$59.3(41.3-86.4)$} & 0.277 \\
\hline \multicolumn{6}{|l|}{ Gender } \\
\hline $\begin{array}{l}\text { Male } \\
\text { Female }\end{array}$ & $\begin{array}{l}23 \\
24\end{array}$ & $\begin{array}{l}49 \\
51\end{array}$ & $\begin{array}{l}22 \\
36\end{array}$ & $\begin{array}{l}38 \\
62\end{array}$ & 0.322 \\
\hline \multicolumn{6}{|l|}{ T-classification } \\
\hline $\begin{array}{l}\text { T1 } \\
\text { T2 } \\
\text { T3 } \\
\text { T4 }\end{array}$ & $\begin{array}{r}1 \\
20 \\
18 \\
8\end{array}$ & $\begin{array}{r}2 \\
43 \\
38 \\
17\end{array}$ & $\begin{array}{r}0 \\
29 \\
19 \\
10\end{array}$ & $\begin{array}{r}0 \\
50 \\
33 \\
17\end{array}$ & 0.837 \\
\hline \multicolumn{6}{|l|}{ N-classification } \\
\hline $\begin{array}{l}\text { N0 } \\
\text { N1 } \\
\text { N2 } \\
\text { N3 } \\
\text { Nx }\end{array}$ & $\begin{array}{r}22 \\
13 \\
9 \\
3 \\
0\end{array}$ & $\begin{array}{r}47 \\
28 \\
19 \\
6 \\
0\end{array}$ & $\begin{array}{r}18 \\
19 \\
9 \\
10 \\
2\end{array}$ & $\begin{array}{r}31 \\
33 \\
16 \\
17 \\
3\end{array}$ & 0.103 \\
\hline
\end{tabular}

\section{UICC stage}

\begin{tabular}{|l|r|r|r|r|}
\hline Stage O & 0 & 0 & 0 & 0 \\
Stage I & 0 & 0 & 0 & 0 \\
Stage II & 17 & 36 & 14 & 24 \\
Stage III & 30 & 64 & 42 & 72 \\
Stage IV & 0 & 0 & 0 & 0 \\
Not known & 0 & 0 & 2 & 3 \\
\hline
\end{tabular}

\section{Primary tumour site}

\begin{tabular}{|c|c|c|c|c|c|}
\hline $\begin{array}{l}\text { Anal canal } \\
\text { Anal margin } \\
\text { Both }\end{array}$ & $\begin{array}{r}40 \\
5 \\
2\end{array}$ & $\begin{array}{r}85 \\
11 \\
4\end{array}$ & $\begin{array}{r}50 \\
5 \\
3\end{array}$ & $\begin{array}{r}86 \\
9 \\
5\end{array}$ & 0.957 \\
\hline \multicolumn{6}{|l|}{ HIV status } \\
\hline $\begin{array}{l}\text { Negative } \\
\text { Positive } \\
\text { Unknown }\end{array}$ & $\begin{array}{r}12 \\
7 \\
28\end{array}$ & $\begin{array}{l}26 \\
15 \\
60\end{array}$ & $\begin{array}{r}27 \\
4 \\
27\end{array}$ & $\begin{array}{r}47 \\
7 \\
47\end{array}$ & 0.078 \\
\hline
\end{tabular}

\section{SCC tumour marker}

Normal $\left(<2.0 \mu \mathrm{gl}^{-1}\right)$

Elevated $\left(\geqslant 2.0 \mu \mathrm{gl}^{-1}\right)$

Unknown

\begin{tabular}{|r|r|r}
\hline 24 & 51 & 36 \\
22 & 47 & 19 \\
1 & 2 & 3 \\
\hline
\end{tabular}

\begin{tabular}{r|r|r}
\hline 36 & 62 & 0.223 \\
19 & 33 & \\
3 & 5 & \\
\hline
\end{tabular}

\section{$D P Y D * 2 A$ genotype}

\section{Wild type}

Heterozygous

Unknown

\begin{tabular}{r|r|r|r|r}
7 & 15 & 56 & 97 & 1.000 \\
0 & 0 & 1 & 2 & \\
40 & 85 & 1 & 2 & \\
\hline
\end{tabular}

\section{Radiation technique}

\begin{tabular}{|c|c|c|c|c|c|}
\hline $\begin{array}{l}\text { CF-RT } \\
\text { IMRT }\end{array}$ & $\begin{array}{l}24 \\
23\end{array}$ & $\begin{array}{l}51 \\
49\end{array}$ & $\begin{array}{r}0 \\
58\end{array}$ & $\begin{array}{r}0 \\
100\end{array}$ & - \\
\hline
\end{tabular}

\section{Radiation dose}

\begin{tabular}{|c|c|c|c|c|}
\hline Surdosage given? & $5-F U+C F-R T$ & $5-F U+I M R T$ & Capecitabine + IMRT & \\
\hline $\begin{array}{l}\text { Yes } \\
\text { No }\end{array}$ & $\begin{array}{c}24(100 \%) \\
0(0 \%)\end{array}$ & $\begin{array}{c}19(83 \%) \\
4(17 \%)\end{array}$ & $\begin{array}{l}32(55 \%) \\
26(45 \%)\end{array}$ & - \\
\hline Total radiation dose to primary tumour, median (range) & $64.8(64.8-66.6)$ & $64.8(59.4-68.4)$ & $64.8(59.4-70.2)$ & - \\
\hline Total radiation dose to LNs, median (range) & $64.8(45.0-66.6)$ & $54.9(49.5-58.5)$ & $54.9(49.5-60.3)$ & - \\
\hline
\end{tabular}




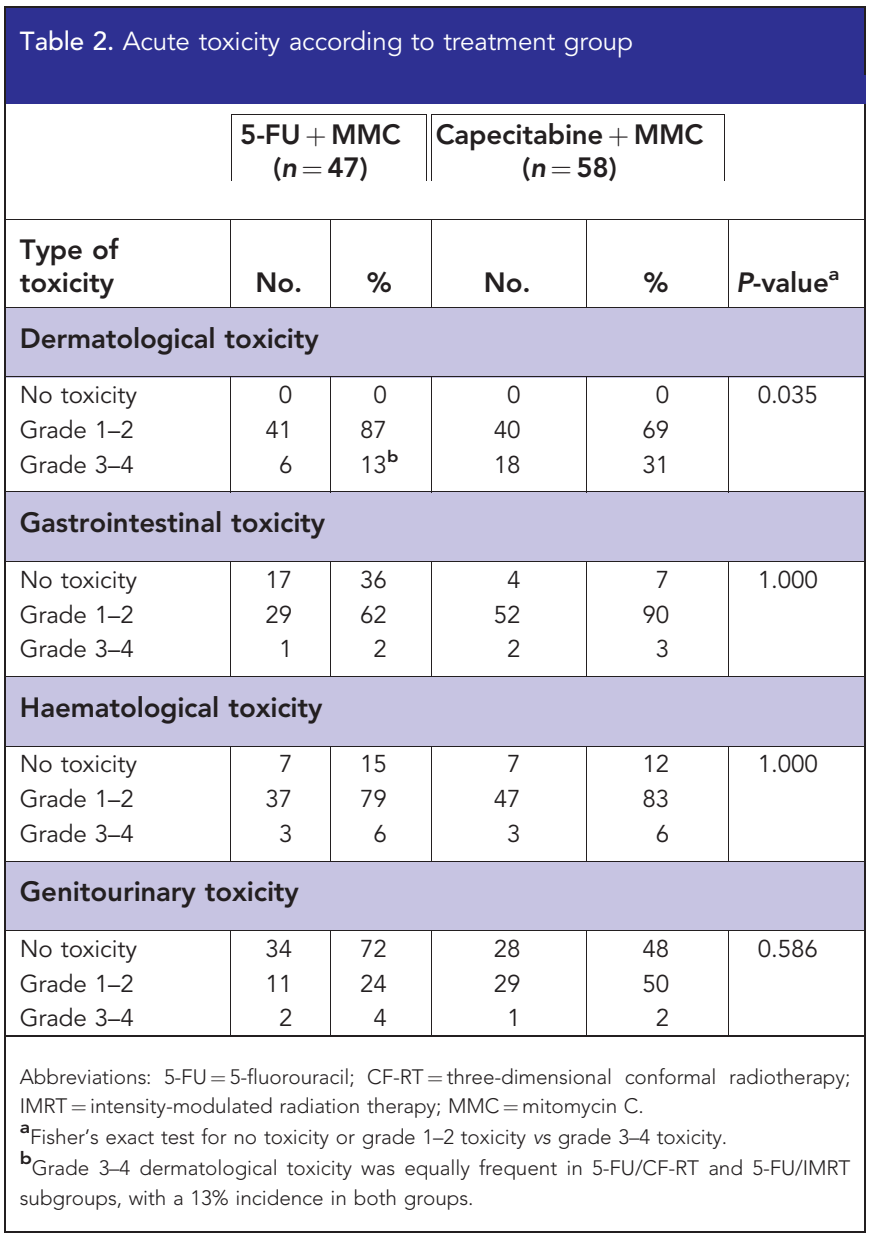

in radiation technique/schedule, as in the 5-FU group there was no effect of radiation technique on the incidence of grade 3-4 dermatological toxicity. In another study, in which capecitabine was combined with conventional radiotherapy, and applied without a treatment gap as in this study, a comparable rate of grade $\geqslant 3$ dermatological toxicity (38\%) was found (Glynne-Jones et al, 2008). Late toxicity was not taken into account in this study and deserves attention in future studies. An important question is how the biological effects of bi-daily capecitabine relate to those of a schedule in which 5 -FU is given in week 1 and 5 . To our knowledge, there are no studies comparing tissue levels of active metabolites of 5-FU (e.g. FdUMP) after continuous infusion of 5-FU compared with bi-daily capecitabine. For several reasons, however, it is likely that cumulative exposure of tumour to 5-FU's active metabolites is at least as high with bi-daily capecitabine at $825 \mathrm{mg} \mathrm{m}^{-2}$ on weekdays as with continuously infused 5-FU at $750 \mathrm{mg} \mathrm{m}^{-2}$ for 5 days in week 1 and 5. First, the dose of capecitabine that is used is at or close to the maximum tolerable dose (Glynne-Jones et al, 2006; Deenen et al, 2013). And, while after administration of 5-FU, the relative exposure of normal and tumour tissue to 5 -FU is equal (Kovach and Beart, 1989), after administration of capecitabine exposure to 5-FU was found to be higher in tumour than in adjacent healthy tissue, in colorectal tumours (Schüller et al, 2000). In addition, there is preclinical evidence that radiation combined with capecitabine (and not with 5-FU) has synergistic antitumour activity due to upregulation of thymidine phosphorylase (which converts $5^{\prime}$-deoxy-5-fluorouridine into 5-FU) by irradiation, theoretically leading to higher concentrations of 5-FU in tumour tissue (Sawada et al, 1999). Importantly, the cumulative dose of capecitabine that is used, relative to $5-\mathrm{FU}$ in the traditional schedule, is in the same range as
Table 3. Characteristics of patients without clinical complete response

\begin{tabular}{|c|c|c|c|c|c|}
\hline \multirow[b]{2}{*}{ Characteristic } & \multicolumn{2}{|c|}{$\begin{array}{c}5-\mathrm{FU}+\mathrm{MMC} \\
(n=5)\end{array}$} & \multicolumn{2}{|c|}{$\begin{array}{l}\text { Capecitabine } \\
+ \text { MMC }(n=6)\end{array}$} & \multirow[b]{2}{*}{$P$-value } \\
\hline & No. & $\%$ & No. & $\%$ & \\
\hline Age (years), median (range) & \multicolumn{2}{|c|}{$65.6(36.8-73.5)$} & \multicolumn{2}{|c|}{$56.2(41.3-65.1)$} & 0.545 \\
\hline \multicolumn{6}{|l|}{ Gender } \\
\hline Male & 3 & 60 & 5 & 83 & \multirow{2}{*}{0.559} \\
\hline Female & 2 & 40 & 1 & 17 & \\
\hline \multicolumn{6}{|l|}{ T-classification } \\
\hline T1 & 0 & 0 & 0 & 0 & \multirow[t]{4}{*}{0.177} \\
\hline $\mathrm{T} 2$ & 2 & 40 & 0 & 0 & \\
\hline T3 & 2 & 40 & 3 & 50 & \\
\hline $\mathrm{T} 4$ & 1 & 20 & 3 & 50 & \\
\hline \multicolumn{6}{|l|}{ N-classification } \\
\hline No & 2 & 40 & 1 & 17 & \multirow[t]{4}{*}{0.086} \\
\hline N1 & 1 & 20 & 0 & 0 & \\
\hline N2 & 2 & 40 & 2 & 33 & \\
\hline N3 & 0 & 0 & 3 & 50 & \\
\hline \multicolumn{6}{|l|}{ HIV status } \\
\hline Negative & 0 & 0 & 4 & 67 & \multirow[t]{3}{*}{0.333} \\
\hline Positive & 1 & 20 & 1 & 17 & \\
\hline Not known & 4 & 80 & 1 & 17 & \\
\hline \multicolumn{6}{|l|}{ Primary tumor site } \\
\hline Anal canal & 6 & 100 & 6 & 100 & \multirow[t]{3}{*}{1.000} \\
\hline Anal margin & 0 & 0 & 0 & 0 & \\
\hline Both & 0 & 0 & 0 & 0 & \\
\hline
\end{tabular}

the cumulative dose of capecitabine relative to 5-FU in the neoadjuvant treatment of rectal cancer (Hofheinz et al, 2012).

In an exploratory pharmacogenetic analysis, we showed that the low expression TYMS VNTR genotype was associated with higher rates of severe toxicity. A recently published large clinical study and meta-analysis confirms the validity of this association (Rosmarin et al, 2014). We also found that the GSTT1 NULL genotype was associated with severe dermatological toxicity. This may be explained by the role of glutathione S-transferase enzymes in counteracting radiation-induced oxidative stress, and is in line with previous reports (Yoon et al, 2011). We did not confirm our previous observation of the GSTP1 313A $>$ G polymorphism being associated with response (Deenen et al, 2013).

Several important limitations of this study should be mentioned. The sample size does not permit to statistically demonstrate noninferiority of capecitabine to 5-FU. Owing to the low incidence of $\mathrm{AC}$ and a low failure rate after chemoradiotherapy, a noninferiority study would be very difficult to undertake. For this reason, treatment decisions will need to be based on retrospective studies and institutional experiences such as presented here. Our patient groups were treated serially in time and we cannot rule out improvement of health care during this time period. However, the time frame in which patients were treated is relatively small, and all patients were treated by a multidisciplinary team that discusses the patients weekly. We therefore assume that the quality of medical care did not change to the extent that it would confound the results of the study. Although we considered all consecutively treated patients, some selection bias might have been introduced by 

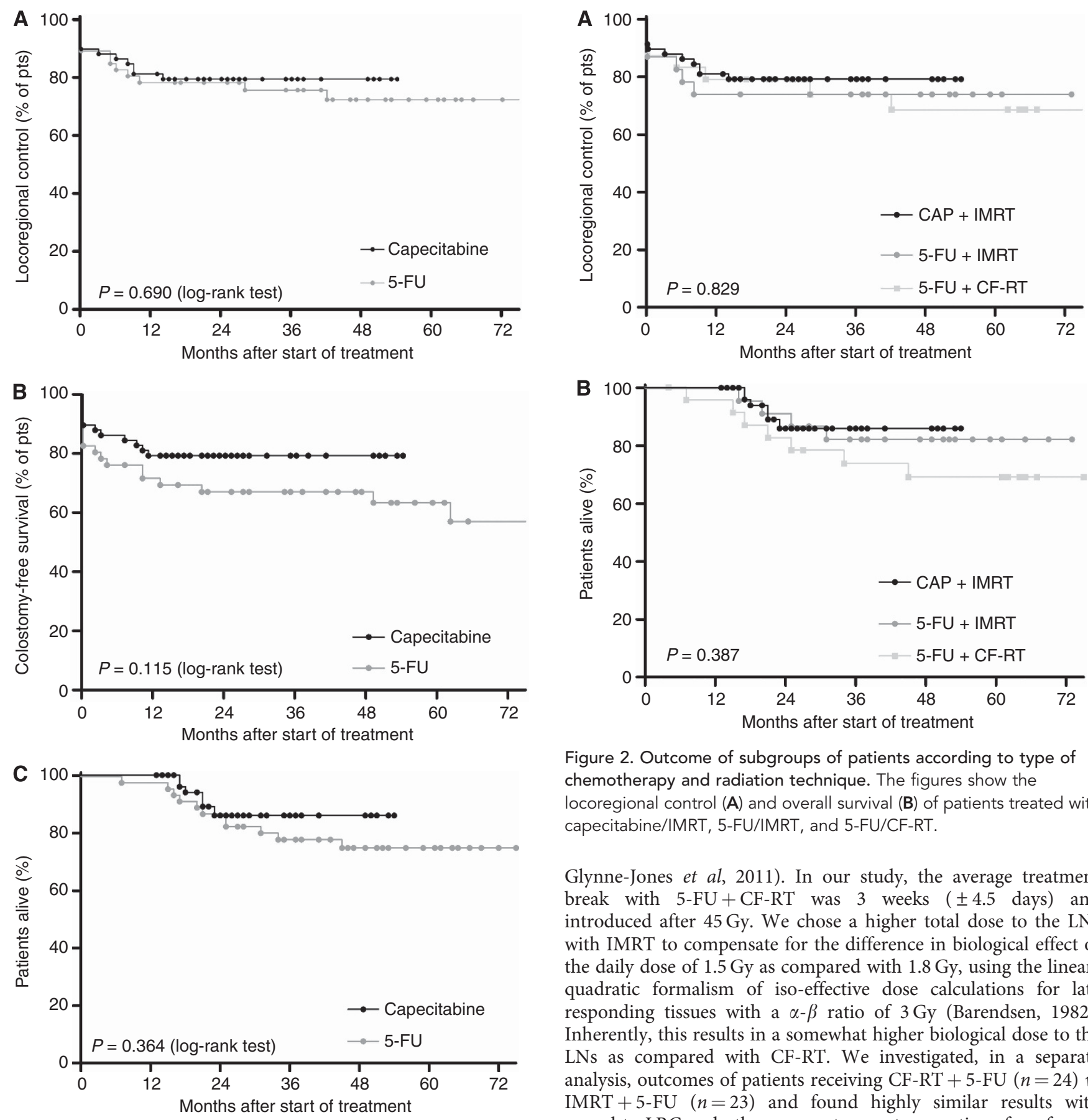

Figure 2. Outcome of subgroups of patients according to type of chemotherapy and radiation technique. The figures show the locoregional control (A) and overall survival (B) of patients treated with capecitabine/IMRT, 5-FU/IMRT, and 5-FU/CF-RT.

Glynne-Jones et al, 2011). In our study, the average treatment break with 5-FU + CF-RT was 3 weeks ( \pm 4.5 days) and introduced after $45 \mathrm{~Gy}$. We chose a higher total dose to the LNs with IMRT to compensate for the difference in biological effect of the daily dose of $1.5 \mathrm{~Gy}$ as compared with $1.8 \mathrm{~Gy}$, using the linearquadratic formalism of iso-effective dose calculations for late responding tissues with a $\alpha-\beta$ ratio of $3 \mathrm{~Gy}$ (Barendsen, 1982). Inherently, this results in a somewhat higher biological dose to the LNs as compared with CF-RT. We investigated, in a separate analysis, outcomes of patients receiving CF-RT $+5-\mathrm{FU}(n=24)$ vs IMRT + 5-FU $(n=23)$ and found highly similar results with regard to LRC and other parameters, not suggestive of confounding by radiation technique. Lastly, the duration of follow-up of patients treated with capecitabine was relatively short. It has, however, been demonstrated that the CCR rate is a good predictor for disease-free survival (Deniaud-Alexandre et al, 2003) and, that most locoregional failures occur within the first 2 years after treatment (UKCCCR Anal Cancer Trial Working Party, 1996; Bartelink et al, 1997).

initially excluding six patients from treatment with capecitabine. However, the proportion of these patients that was disease-free and alive at last follow-up (83\%) was comparable to the overall population. The type of radiotherapy that patients received may also have affected outcome. Superior outcome with IMRT has been claimed, due to the lack of a treatment break and shorter overall treatment time (Pepek et al, 2010; Bazan et al, 2011). However, inferior outcomes with CF-RT have mainly been demonstrated with longer treatment gaps ( $\geqslant 5$ weeks), or when the break is introduced early in the course of treatment (Weber et al, 2001;

\section{CONCLUSION}

In this retrospective analysis, we show for the first time that $\mathrm{AC}$ patients treated with capecitabine fare equally well as patients treated with 5-FU in terms of CCR rate, LRC and OS. Despite the above-mentioned limitations, we believe that the conclusions drawn from this study with regard to the primary end points 
Table 4. Associations of genetic polymorphisms in GSTT1, GSTM1, GSTP1 and TYMS with outcome and toxicity

Clinical response

Overall toxicity

\begin{tabular}{|c|c|c|c|c|c|c|}
\hline Polymorphism & PR & CR & $P$-value ${ }^{a}$ & Grade $0-2$ & Grade 3-4 & P-value ${ }^{a}$ \\
\hline \multicolumn{7}{|c|}{ GSTT1 (deletion) } \\
\hline $\begin{array}{l}\text { Not NULL } \\
\text { NULL }\end{array}$ & $\begin{array}{l}7(9 \%) \\
3(14 \%)\end{array}$ & $\begin{array}{l}68(91 \%) \\
18(86 \%)\end{array}$ & 0.686 & $\begin{array}{l}55(72 \%) \\
10(48 \%)\end{array}$ & $\begin{array}{l}21(28 \%) \\
11(52 \%)\end{array}$ & 0.065 \\
\hline
\end{tabular}

\section{GSTM1 (deletion)}

\begin{tabular}{|l|l|l|l|l|l|l|}
\hline Not NULL & $4(11 \%)$ & $34(89 \%)$ & 1.000 & $26(68 \%)$ & $12(32 \%)$ & 0.827 \\
NULL & $6(10 \%)$ & $52(90 \%)$ & & $38(66 \%)$ & $20(35 \%)$ & \\
\hline
\end{tabular}

\section{GSTP1 313A > G}

\begin{tabular}{|c|c|c|c|c|c|c|}
\hline $\begin{array}{l}\mathrm{AA} \\
\mathrm{AG} \text { or } \mathrm{GG}\end{array}$ & $\begin{array}{l}5(12 \%) \\
5(9 \%)\end{array}$ & $\begin{array}{l}38 \text { (88\%) } \\
48 \text { (91\%) }\end{array}$ & 0.749 & $\begin{array}{l}33(77 \%) \\
32(60 \%)\end{array}$ & $\begin{array}{l}10(23 \%) \\
21(40 \%)\end{array}$ & 0.124 \\
\hline \multicolumn{7}{|c|}{ TYMS 3'-UTR 6-bp ins/del } \\
\hline $\begin{array}{l}\text { Ins/Ins } \\
\text { Ins/Del or Del/Del }\end{array}$ & $\begin{array}{l}6(15 \%) \\
4(7 \%)\end{array}$ & $\begin{array}{l}33(85 \%) \\
53(93 \%)\end{array}$ & 0.307 & $\begin{array}{l}25 \text { (64\%) } \\
40 \text { (70\%) }\end{array}$ & $\begin{array}{l}14(36 \%) \\
17(30 \%)\end{array}$ & 0.657 \\
\hline \multicolumn{7}{|c|}{ TYMS 5'-UTR VNTR ${ }^{b}$} \\
\hline $\begin{array}{l}\text { High expressor } \\
\text { Low expressor }\end{array}$ & $\begin{array}{l}4(12 \%) \\
6(10 \%)\end{array}$ & $\begin{array}{l}30 \text { (88\%) } \\
56(90 \%)\end{array}$ & 0.739 & $\begin{array}{l}28(82 \%) \\
37(60 \%) \\
\end{array}$ & $\begin{array}{r}6(18 \%) \\
25(40 \%) \\
\end{array}$ & 0.025 \\
\hline
\end{tabular}

Table 5. Associations of genetic polymorphisms in GSTT1, GSTM1, GSTT1, and TYMS with individual types of toxicity

\begin{tabular}{|c|c|c|c|c|c|c|c|c|c|c|c|c|}
\hline & \multicolumn{3}{|c|}{ Dermatological toxicity } & \multicolumn{3}{|c|}{ Haematological toxicity } & \multicolumn{3}{|c|}{ Gastrointestinal toxicity } & \multicolumn{3}{|c|}{ Genitourinary toxicity } \\
\hline & $\begin{array}{c}\text { Grade } \\
0-2\end{array}$ & $\begin{array}{c}\text { Grade } \\
3-4\end{array}$ & $P$-value ${ }^{a}$ & $\begin{array}{c}\text { Grade } \\
0-2\end{array}$ & $\begin{array}{c}\text { Grade } \\
3-4\end{array}$ & $P$-value ${ }^{a}$ & $\begin{array}{c}\text { Grade } \\
0-2\end{array}$ & $\begin{array}{c}\text { Grade } \\
3-4\end{array}$ & $P$-value ${ }^{a}$ & $\begin{array}{c}\text { Grade } \\
0-2\end{array}$ & $\begin{array}{c}\text { Grade } \\
3-4\end{array}$ & $P$-value ${ }^{a}$ \\
\hline \multicolumn{13}{|l|}{ GSTT1 } \\
\hline $\begin{array}{l}\text { Not NULL } \\
\text { NULL }\end{array}$ & $\begin{array}{l}61(81 \%) \\
12(57 \%)\end{array}$ & $\begin{array}{r}14(19 \%) \\
9(43 \%)\end{array}$ & 0.040 & $\begin{array}{l}72(96 \%) \\
19(90 \%)\end{array}$ & $\begin{array}{l}3(4 \%) \\
2(10 \%)\end{array}$ & 0.300 & \begin{tabular}{|l}
$73(97 \%)$ \\
$20(95 \%)$
\end{tabular} & $\begin{array}{l}2(3 \%) \\
1(5 \%)\end{array}$ & 0.527 & \begin{tabular}{|l|}
73 (97\%) \\
20 (95\%)
\end{tabular} & $\begin{array}{l}2(3 \%) \\
1(5 \%)\end{array}$ & 0.527 \\
\hline \multicolumn{13}{|l|}{ GSTM1 } \\
\hline $\begin{array}{l}\text { Not NULL } \\
\text { NULL }\end{array}$ & $\begin{array}{l}29(76 \%) \\
44(76 \%)\end{array}$ & $\begin{array}{r}9(24 \%) \\
14(24 \%)\end{array}$ & 1.000 & $\begin{array}{l}36(95 \%) \\
55(95 \%)\end{array}$ & $\begin{array}{l}2(5 \%) \\
3(5 \%)\end{array}$ & 1.000 & \begin{tabular}{|l}
$36(95 \%)$ \\
$57(98 \%)$
\end{tabular} & $\begin{array}{l}2(5 \%) \\
1(2 \%)\end{array}$ & 0.560 & \begin{tabular}{|l}
$38(100 \%)$ \\
55 (95\%)
\end{tabular} & $\begin{array}{l}0(0 \%) \\
3(5 \%)\end{array}$ & 0.275 \\
\hline \multicolumn{13}{|l|}{ GSTP1 } \\
\hline $\begin{array}{l}A A \\
A G \text { or } G G\end{array}$ & $\begin{array}{l}36(84 \%) \\
38(72 \%)\end{array}$ & $\begin{array}{r}7(16 \%) \\
15(28 \%)\end{array}$ & 0.223 & $\begin{array}{l}42(98 \%) \\
49(92 \%)\end{array}$ & $\begin{array}{l}1(2 \%) \\
4(8 \%)\end{array}$ & 0.376 & \begin{tabular}{|l}
42 (98\%) \\
51 (96\%)
\end{tabular} & $\begin{array}{l}1(2 \%) \\
2(4 \%)\end{array}$ & 1.000 & \begin{tabular}{|l}
42 (98\%) \\
51 (96\%)
\end{tabular} & $\begin{array}{l}1(2 \%) \\
2(4 \%)\end{array}$ & 1.000 \\
\hline \multicolumn{13}{|c|}{ TYMS 3'-UTR 6-bp ins/del } \\
\hline $\begin{array}{l}\text { Ins/Ins } \\
\text { Ins/Del or Del/Del }\end{array}$ & $\begin{array}{l}29(74 \%) \\
45(79 \%)\end{array}$ & $\begin{array}{l}10(26 \%) \\
12(21 \%)\end{array}$ & 0.628 & $\begin{array}{l}36(92 \%) \\
55(96 \%)\end{array}$ & $\begin{array}{l}3(8 \%) \\
2(4 \%)\end{array}$ & 0.393 & $\begin{array}{l}38(97 \%) \\
55(96 \%)\end{array}$ & $\begin{array}{l}1(3 \%) \\
2(4 \%)\end{array}$ & 1.000 & \begin{tabular}{|l}
$37(95 \%)$ \\
$56(98 \%)$
\end{tabular} & $\begin{array}{l}2(5 \%) \\
1(2 \%)\end{array}$ & 0.564 \\
\hline \multicolumn{13}{|c|}{ TYMS 5'-UTR VNTR ${ }^{b}$} \\
\hline $\begin{array}{l}\text { High expressor } \\
\text { Low expressor }\end{array}$ & $\begin{array}{l}30(88 \%) \\
44(71 \%) \\
\end{array}$ & $\begin{array}{r}4(12 \%) \\
18(29 \%) \\
\end{array}$ & 0.075 & $\begin{array}{l}32(94 \%) \\
59(95 \%) \\
\end{array}$ & $\begin{array}{l}2(6 \%) \\
3(5 \%) \\
\end{array}$ & 1.000 & \begin{tabular}{|l|}
$34(100 \%)$ \\
59 (95\%) \\
\end{tabular} & $\begin{array}{l}0(0 \%) \\
3(5 \%) \\
\end{array}$ & 0.550 & \begin{tabular}{|l}
$34(100 \%)$ \\
$59(95 \%)$ \\
\end{tabular} & $\begin{array}{l}0(0 \%) \\
3(5 \%) \\
\end{array}$ & 0.550 \\
\hline $\begin{array}{l}\text { Abbreviations: GSTM1 } \\
\text { of } 28 \text {-bp tandem repe } \\
\mathbf{a}_{\text {Fisher's exact test (tw }} \\
{ }^{2} \text { Low TYMS expressio }\end{array}$ & $\begin{array}{l}\text { lutathione } \\
\text { ded). }\end{array}$ & ransferase & ; GSTP1 & & & & nione S- & & & & & \\
\hline
\end{tabular}


are valid. Our population reflects the treatment of AC in daily clinical practice, and we conclude that capecitabine $825 \mathrm{mg} \mathrm{m}^{-2}$ b.i.d. on radiation days can be used instead of continuous intravenous 5-FU in combination with MMC and IMRT in the treatment of locally advanced AC.

\section{CONFLICT OF INTEREST}

The authors declare no conflict of interest.

\section{REFERENCES}

Ambrosone CB, Tian C, Ahn J, Kropp S, Helmbold I, von Fournier D, Haase W, Sautter-Bihl ML, Wenz F, Chang-Claude J (2006) Genetic predictors of acute toxicities related to radiation therapy following lumpectomy for breast cancer: a case-series study. Breast Cancer Res 8: R40.

Barendsen GW (1982) Dose fractionation, dose rate and iso-effect relationships for normal tissue responses. Int J Radiat Oncol Biol Phys 8: 1981-1997.

Bartelink H, Roelofsen F, Eschwege F, Rougier P, Bosset JF, Gonzalez DG, Peiffert D, van Glabbeke M, Pierart M (1997) Concomitant radiotherapy and chemotherapy is superior to radiotherapy alone in the treatment of locally advanced anal cancer: results of a phase III randomized trial of the European Organization for Research and Treatment of Cancer Radiotherapy and Gastro. J Clin Oncol 15: 2040-2049.

Bazan JG, Hara W, Hsu A, Kunz PA, Ford J, Fisher Ga, Welton ML, Shelton A, Kapp DS, Koong AC, Goodman Ka, Chang DT (2011) Intensitymodulated radiation therapy versus conventional radiation therapy for squamous cell carcinoma of the anal canal. Cancer 117: 3342-3351.

Deenen MJ, Dewit L, Boot H, Beijnen JH, Schellens JHM, Cats A (2013) Simultaneous integrated boost-intensity modulated radiation therapy with concomitant capecitabine and mitomycin $\mathrm{C}$ for locally advanced anal carcinoma: a phase 1 study. Int J Radiat Oncol Biol Phys 85: e201-e207.

Deniaud-Alexandre E, Touboul E, Tiret E, Sezeur A, Houry S, Gallot D, Parc R, Huang R, Qu S-H, Huart J, Pène F, Schlienger M (2003) Results of definitive irradiation in a series of 305 epidermoid carcinomas of the anal canal. Int J Radiat Oncol Biol Phys 56: 1259-1273.

Glynne-Jones R, Dunst J, Sebag-Montefiore D (2006) The integration of oral capecitabine into chemoradiation regimens for locally advanced rectal cancer: how successful have we been? Ann Oncol 17: 361-371.

Glynne-Jones R, Meadows H, Wan S, Gollins S, Leslie M, Levine E, McDonald AC, Myint S, Samuel L, Sebag-Montefiore D (2008) EXTRA-a multicenter phase II study of chemoradiation using a 5 day per week oral regimen of capecitabine and intravenous mitomycin C in anal cancer. Int J Radiat Oncol Biol Phys 72: 119-126.

Glynne-Jones R, Sebag-Montefiore D, Adams R, McDonald A, Gollins S, James R, Northover JMa, Meadows HM, Jitlal M (2011) "Mind the gap"-the impact of variations in the duration of the treatment gap and overall treatment time in the first UK Anal Cancer Trial (ACT I). Int J Radiat Oncol Biol Phys 81: 1488-1494.

Gunderson LL, Winter Ka, Ajani Ja, Pedersen JE, Moughan J, Benson AB, Thomas CR, Mayer RJ, Haddock MG, Rich TA, Willett CG (2012) Long-term update of US GI intergroup RTOG 98-11 phase III trial for anal carcinoma: survival, relapse, and colostomy failure with concurrent chemoradiation involving fluorouracil/mitomycin versus fluorouracil/ cisplatin. J Clin Oncol 30: 4344-4351.

Hofheinz R-D, Wenz F, Post S, Matzdorff A, Laechelt S, Hartmann JT, Müller L, Link H, Moehler M, Kettner E, Fritz E, Hieber U, Lindemann HW, Grunewald M, Kremers S, Constantin C, Hipp M, Hartung G, Gencer D, Kienle P, Burkholder I, Hochhaus A (2012) Chemoradiotherapy with capecitabine versus fluorouracil for locally advanced rectal cancer: a randomised, multicentre, non-inferiority, phase 3 trial. Lancet Oncol 2045: $1-10$.

James RD, Glynne-Jones R, Meadows HM, Cunningham D, Myint AS, Saunders MP, Maughan T, McDonald A, Essapen S, Leslie M, Falk S,
Wilson C, Gollins S, Begum R, Ledermann J, Kadalayil L, Sebag-Montefiore D (2013) Mitomycin or cisplatin chemoradiation with or without maintenance chemotherapy for treatment of squamouscell carcinoma of the anus (ACT II): a randomised, phase 3, open-label, $2 \times 2$ factorial trial. Lancet Oncol 14: 516-524.

Kovach JS, Beart RW (1989) Cellular pharmacology of fluorinated pyrimidines in vivo in man. Invest New Drugs 7: 13-25.

Mahimkar MB, Samant TA, Kannan S, Tulsulkar J, Pai PS, Anantharaman D (2011) Polymorphisms in GSTM1 and XPD genes predict clinical outcome in advanced oral cancer patients treated with postoperative radiotherapy. Mol Carcinog 51: 1-10.

Mandola MV, Stoehlmacher J, Muller-weeks S, Cesarone G, Yu MC, Lenz H, Ladner RD (2003) A novel single nucleotide polymorphism within the $5^{\prime}$ tandem repeat polymorphism of the thymidylate synthase gene abolishes USF-1 binding and alters transcriptional activity. Cancer Res 63(11): 2898-2904.

Netherlands Cancer Registry: http://www.cijfersoverkanker.nl/. Accessed on: 14 August 2013.

Nigro ND, Seydel HG, Considine B, Vaitkevicius VK, Leichman L, Kinzie JJ (1983) Combined preoperative radiation and chemotherapy for squamous cell carcinoma of the anal canal. Cancer 51: 1826-1829.

Pepek JM, Willett CG, Wu QJ, Yoo S, Clough RW, Czito BG (2010) Intensity-modulated radiation therapy for anal malignancies: a preliminary toxicity and disease outcomes analysis. Int J Radiat Oncol Biol Phys 78: 1413-1419.

Pullarkat ST, Stoehlmacher J, Ghaderi V, Xiong YP, Ingles SA, Sherrod A, Warren R, Tsao-Wei D, Groshen S, Lenz HJ (2001) Thymidylate synthase gene polymorphism determines response and toxicity of 5-FU chemotherapy. Pharmacogenomics J 1: 65-70.

Rosmarin D, Palles C, Church D, Domingo E, Jones A, Johnstone E, Wang H, Love S, Julier P, Scudder C, Nicholson G, Gonzalez-Neira A, Martin M, Sargent D, Green E, McLeod H, Zanger UM, Schwab M, Braun M, Seymour M, Thompson L, Lacas B, Boige V, Ribelles N, Afzal S, Enghusen H, Astrup Jensen S, Etienne-Grimaldi M-C, Milano G, Wadelius M, Glimelius B, Garmo H, Gusella M, Lecomte T, Laurent-Puig P, Martinez-Balibrea E, Sharma R, Garcia-Foncillas J, Kleibl Z, Morel A, Pignon J-P, Midgley R, Kerr D, Tomlinson I (2014) Genetic markers of toxicity from capecitabine and other fluorouracil-based regimens: investigation in the QUASAR2 study, systematic review, and metaanalysis. J Clin Oncol 32(10): 1031-1039.

Sawada N, Ishikawa T, Sekiguchi F, Tanaka Y, Ishitsuka H (1999) X-ray irradiation induces thymidine phosphorylase and enhances the efficacy of capecitabine (Xeloda) in human cancer xenografts. Clin Cancer Res 5 : 2948-2953.

Schüller J, Cassidy J, Dumont E, Roos B, Durston S, Banken L, Utoh M, Mori K, Weidekamm E, Reigner B (2000) Preferential activation of capecitabine in tumor following oral administration to colorectal cancer patients. Cancer Chemother Pharmacol 45: 291-297.

UKCCCR Anal Cancer Trial Working Party (1996) Epidermoid anal cancer: results from the UKCCCR randomised trial of radiotherapy alone versus radiotherapy, 5-fluorouracil, and mitomycin. Lancet 348 : 1049-1054.

Weber DC, Kurtz JM, Allal AS (2001) The impact of gap duration on local control in anal canal carcinoma treated by split-course radiotherapy and concomitant chemotherapy. Int J Radiat Oncol Biol Phys 50: $675-680$.

Yoon HH, Catalano PJ, Murphy KM, Skaar TC, Philips S, Powell M, Montgomery Ea, Hafez MJ, Offer SM, Liu G, Meltzer SJ, Wu X, Forastiere Aa, Benson AB, Kleinberg LR, Gibson MK (2011) Genetic variation in DNA-repair pathways and response to radiochemotherapy in esophageal adenocarcinoma: a retrospective cohort study of the Eastern Cooperative Oncology Group. BMC Cancer 11: 176.

This work is published under the standard license to publish agreement. After 12 months the work will become freely available and the license terms will switch to a Creative Commons AttributionNonCommercial-Share Alike 3.0 Unported License. 